\title{
Glycemia Targeted Specialized Nutrition (GTSN) improves postprandial glycemia and GLP-1 with similar appetitive responses compared to a healthful whole food breakfast in persons with type 2 diabetes: a randomized, controlled trial
}

Amy A. Devitt ${ }^{1 *}$, Jeffery S. Oliver ${ }^{1}$, Refaat A. Hegazi ${ }^{1}$ and Vikkie A. Mustad ${ }^{1}$

*Correspondence: amy.devitt-maicher@abbott.com

${ }^{1}$ Abbott Nutrition, Columbus, OH, USA.

\begin{abstract}
Background: For people with type 2 diabetes mellitus (T2DM), the frequency and/or composition of the morning meal may be especially important as the disease associated hormonal and metabolic perturbations contribute significantly to poor glucose control and weight gain. Few well-controlled studies have evaluated the effects of skipping breakfast and nutrient composition on metabolic outcomes in T2DM. This study evaluated the impact of consuming one of two convenient and healthful breakfast options versus skipping breakfast on postprandial blood glucose, insulin, glucagon-like peptide-1 (GLP-1), total energy intake and appetite.

Materials and methods: This was a randomized, controlled, non-blinded, three- treatment, crossover study conducted at two sites. All subjects $(\mathrm{n}=32)$ had T2DM. On study day mornings, fasted subjects consumed each test meal in random order: the two nutritional interventions administered were (1) a typical whole food breakfast meal consisting of oatmeal (OAT; 200 kcals, $8 \mathrm{~g}$ protein, $36 \mathrm{~g}$ carbohydrate (CHO), $6 \mathrm{~g}$ fiber, $4 \mathrm{~g}$ fat) and (2) a calorically-matched glycemia-targeted specialized-nutrition (GTSN; $216 \mathrm{kcals}, 10 \mathrm{~g}$ protein, $29 \mathrm{~g}$ CHO, $2 \mathrm{~g}$ fiber and $8 \mathrm{~g}$ fat) compared to (3) skipping breakfast (SBF). Blood samples for measurement of plasma glucose, insulin and GLP-1 and appetitive responses were collected at baseline (pre-meal) and after consumption of the test meal over 180 minutes.

$\underline{\text { Results: }}$ Postprandial plasma glucose positive area under the curve (pAUC) mean was significantly reduced by $38 \%$ (based on individual percent changes) after GTSN compared to OAT. The SBF had the smallest glucose pAUC mean of all interventions. GLP-1 postprandial pAUC median of individual percent changes was significantly elevated after the consumption of GTSN by $280 \%$ compared to OAT and $995 \%$ compared to SBF. Subjective hunger pAUC mean was significantly elevated and fullness significantly lower after SBF compared to both the OAT and GTSN. No differences in hunger or fullness were observed between the GTSN and OAT interventions.

Conclusion: This study demonstrated that utilization of GTSN improved glycemic control and elevated GLP-1 levels compared to a healthful breakfast food and breakfast skipping without negatively impacting appetitive response or energy intake. These results suggest that GTSN containing slowly digesting carbohydrates and monounsaturated fatty acids (MUFA) may provide additional metabolic benefits when used as a meal replacement compared to oatmeal and breakfast skipping for people with T2DM.
\end{abstract}

Trial Registry Number: NCT01324921 (http://www.clinicaltrials.gov/)

Keywords: Type-2 diabetes, diabetes specific formula, glucose control, GLP-1, breakfast

\section{Background}

Medical nutrition therapy is a critical part of globally accepted treatment guidelines for type 2 diabetes mellitus (T2DM) [1-6]. An important feature of these nutrition therapeutic guidelines is attention to type and amount of carbohydrate and calorie control leading to weight management. Randomized controlled trials such as the Look AHEAD trial of over 5000 overweight or obese individuals with T2DM $[7,8]$ demonstrate that convenient, prepackaged low-glycemic meal replacements can increase adherence to lifestyle modification resulting in maintenance of weight loss. In the Look AHEAD trial men and women with type 2 diabetes in the intensive lifestyle intervention group, the meal replacements were recommended to be consumed as the breakfast meal and in place of one daily snack. In a smaller study [9], Chinese men and women with T2DM who were provided a low glycemic diabetes meal replacement to replace high glycemic breakfast food items at the morning eating occasion, had improved metabolic responses and glycosylated hemoglobin $(\mathrm{HbA1c})$ was lower $(\mathrm{p}<0.001)$ in the Intervention Group at 12 weeks $(-0.6 \pm 0.1 \%)$ and 24 
weeks $(-0.8 \pm 0.1 \%)$. Additionally, both weight and waist circumferences were also improved in the Intervention Group vs. Reference Group. Several others have also demonstrated successful maintenance of weight loss with the consumption of breakfast [10] and by the use of meal replacements at breakfast and lunch eating occasions in obese T2DM patients [11-13].

Glycemia Targeted Specialized Nutrition (GTSN) such as the meal replacements utilized in the LookAHEAD $[7,8]$ and Sun et al.[9], trials have been included as an integral part of a recently published Transcultural Nutrition Algorithm that advocates lifestyle modification as an adjunct to pharmacotherapy [4-6]. GTSN formulas containing low glycemic index and slowly digested carbohydrates were shown to exert better glycemic management as compared to standard formulas $[\mathbf{9 , 1 4 - 1 9 ]}$ when used as a meal or calorie replacement or as a dietary supplement as part of overall nutritional management of diabetes [reviewed in 16]. However, a comparison of the glycemic response of GTSN to other whole food breakfast choices has not been explored.

The current study was designed to compare the impact of skipping breakfast and a whole food, convenient and healthful breakfast option to a convenient and healthful GTSN on postprandial glycemic, insulinemic, glucagon-like peptide-1 (GLP-1), appetitive responses and total energy intake in people with T2DM.

\section{Study Design and Methods Human subjects}

This was a randomized, controlled non-blinded, three-period, three-treatment, crossover study conducted at two sites in the US. This research was reviewed and approved by an Independent Ethics Committee (Schulmann Associates, IRB, $\mathrm{OH}$ ). Adult subjects ( $\geq 18$ and $\leq 75$ years of age) with T2DM receiving stable doses of oral hypoglycemic medication for at least two months were eligible. Prior to participation in the study, all subjects provided applicable privacy authorization and written informed consent. Additional inclusion criteria were (1) BMI was $>18.5$ and $\leq 35.0 \mathrm{~kg} / \mathrm{m}^{2}$, (2) weight stable for the two months prior to the screening visit, (3) male or a non-pregnant, non-lactating female, at least 6 weeks postpartum prior to screening visit, (4) if on a chronic medication such as an anti-hypertensive, lipid-lowering, thyroid medication or hormone therapy, the dosage was constant for at least two months prior to screening visit, (5) willingness to follow protocol as described, including consumption of study product per protocol and completing any forms needed throughout the study, (6) at least a two week wash-out period between completion of a previous research study that required ingestion of any study food or drug and their start in the current study. Subjects were excluded from the study if one of the following conditions existed: (1) screening $\mathrm{HbA}_{1} \mathrm{c}$ level $\geq 9 \%$ (as assessed by capillary measurement via A1cNow $+{ }^{\oplus}$, Bayer, Healthcare, Berlin, Germany) ; (2) use of exogenous insulin or GLP-1 agonists for glucose control; (3) confirmed type 1 diabetes and/or had history of diabetic ketoacidosis; (4) current infection (requiring medication), inpatient surgery or received systemic corticosteroid treatment (with the exception of inhaled (includes nasal), topical, and ophthalmic steroids) in the last 3 months; or received antibiotics in the last 3 weeks; (5) active malignancy (excluding the following dermal malignancies: basal cell carcinoma, squamous cell carcinoma, carcinoma in-situ of the cervix); (6) significant cardiovascular event within 6 months prior to study entry or history of congestive heart failure; (7) end stage organ failure (such as end stage renal disease) or was post organ transplant; (8) history of renal disease; (9) current hepatic disease; (10) history of severe gastroparesis; (11) a chronic, contagious, infectious disease, such as active tuberculosis, Hepatitis B or C, or HIV; (12) taking any herbals, dietary supplements, or medications, other than anti-hyperglycemic medications, during the past four weeks prior to screening visit that could profoundly affect (in the opinion of the primary investigator) blood glucose; (13) clotting or bleeding disorders (the use of Plavix ${ }^{\circledR}$ or a similar anticoagulant drug with no reported difficulty during blood draws was allowed); (14) allergic or intolerant to any ingredient found in the test meals; (15) habitual use of tobacco products (e.g. cigarettes, pipes, chewing tobacco) or (16) participant in another study that has not been approved as a concomitant study by AN.

Subjects were excluded from the analysis if they (1) did not meet eligibility criteria; (2) have a missing positive AUC for plasma glucose concentration over $0-180$ minutes (from the meal tolerance test (MTT)); (3) did not consume all of the test breakfast or lunch meal, including required beverage, within the allotted time.

\section{Study Treatments}

Three treatments were assessed in random order and were comprised as follows: skipped breakfast (SBF; 12 $\mathrm{fl}$ oz compulsory beverage), oatmeal (OAT; unflavored, unsweetened instant oatmeal \{prepared with $1-1 / 3$ cups (316 $\mathrm{mL}$ ) water and microwaved 2-3 minutes per manufacturer's instructions; The Quaker Oats Company, Chicago, Illinois\} + $12 \mathrm{fl}$ oz of compulsory beverage) or 1 serving of the GTSN (Glucerna Triple Care $\{8 \mathrm{fl}$. oz., Abbott Nutrition, Columbus, Ohio $+4 \mathrm{fl} \mathrm{oz} \mathrm{compulsory} \mathrm{beverage).} \mathrm{The} \mathrm{compulsory}$ beverage was decaffeinated coffee/ tea or water and up to 4 packets of non-caloric sweetener per each subject's preference. Compulsory beverage choice, sweetener usage and total beverage consumption ( 12 fluid ounces total) was constant for a given subject across all three treatments. Macronutrient composition was similar between the two caloric meals (Table 1).

\section{Study procedures}

Eligible subjects were scheduled to report to the study site 
Devitt et al. Journal of Diabetes Research \& Clinical Metabolism 2012,

http://www.hoajonline.com/journals/pdf/2050-0866-1-20.pdf

Table 1. Composition of caloric breakfast treatments

\begin{tabular}{|c|c|c|}
\hline & Oatmeal & $\begin{array}{c}\text { Glycemia-Tar- } \\
\text { geted Specialized } \\
\text { Nutrition (GTSN) }\end{array}$ \\
\hline Serving & $\begin{array}{c}56 \text { g Oatmeal } \\
+316 \mathrm{~mL} \mathrm{H}_{2} 0(11 \mathrm{fl.} \mathrm{oz})\end{array}$ & $230 \mathrm{~mL}$ (8 fl. oz.) \\
\hline Energy (kcal) & 200 & 216 \\
\hline Protein (g) & 8 & 10.0 \\
\hline Carbohydrate (g) & 38 & 29 \\
\hline Dietary fiber (g) & 6 & 2.07 \\
\hline Fat (g) & 4 & 8.1 \\
\hline
\end{tabular}

on three separate mornings after a 8-14 hour overnight fast, with 7-14 days between study visits. During study visits, subjects' medications were reviewed to ensure no changes in hypoglycemic agents and study preparation procedures were documented. Study procedures were similar to those of a standard oral glucose tolerance test [20]. However, postprandial response to a mixed meal or meal skipping was assessed instead of a glucose load. Study preparation required the study subjects to (1) consume at least $150 \mathrm{~g}$ of carbohydrate during the 3 days prior to the study visit, (2) refrain from vigorous physical activity the day before the study visit, and (3) consume the provided snack (180200kcal; 5-8 gram fat7; 20-24 grams carbohydrate; 12-16 grams protein) between 8-10 pm the evening before the visit.

Upon arrival to the study visit, the subject's capillary blood glucose level was obtained to confirm appropriate fasting and if the level was $\geq 60$ and $<300 \mathrm{mg} / \mathrm{dL}$, the subject was allowed to continue with study procedures. In the event that capillary blood glucose was not within the specified range, the subject was required to exit the study. All subjects consumed each of the three treatments per the randomization schedule within 10 minutes and the first intake of food/beverage was set to be time zero. Blood samples for plasma glucose (Glucose hexokinase, UV, Roche Hitachi Modular), serum insulin (Immunometric assay, Siemens Healthcare Diagnostics IMMULITE Series), and plasma GLP-1 (7-36 amide collected in dipeptidyl peptidase-IV containing vaccutainer, ELISA from ALPCO ${ }^{\text {TM }}$ Immunoassays, Salem, NH) were obtained at baseline (right before meal consumption), and postprandially at 30,60,90, 120 , and 180 minutes ( $\pm 5 \mathrm{~min}$ ). All blood analyses were performed at a central laboratory (ICON Central Laboratories, Farmingdale, New York).

Subjective appetitive responses via $100 \mathrm{~mm}$ line visual analog scales were obtained in conjunction with each blood sampling time ( $\pm 10 \mathrm{~min}$ ). Appetitive questionnaires for the six modalities were anchored with the descriptive terms "not at all" and "extremely" for hunger, fullness, desire to eat, thirst and nausea whereas "nothing at all" and "a large amount" were the descriptive anchors for prospective consumption.

\section{Statistical analysis and Calculations}

The methodology for measuring glycemic response was adapted from previous studies $[\mathbf{2 0 , 2 1 ]}$. The primary variable was the positive area under the curve (pAUC) for plasma glucose concentration over 0 to 180 minutes. The power calculation was based on a $20 \%$ reduction of the GTSN pAUC compared with the pAUC from the control in this study (OAT). Assuming a 30\% attrition rate, and keeping the number of subjects enrolled as a multiple of 6 for equal treatment sequence assignment, 36 subjects were targeted for enrollment. Sample size was determined using nQuery Advisor ${ }^{\circ}$ Release 5.0. The primary statistical analysis was on the protocol evaluable data set. Data are presented as Least Squares Means \pm SEM for repeated measures analysis of variance (ANOVA). Statistical analyses were performed using three-treatment, three-period, repeated measures ANOVA with site, treatment and period as fixed effects and subject as random effect. If this test was determined to be inappropriate due to non-normality, then three pairwise treatment differences were analyzed using signed rank tests.

Calculations for area under the curve from 0-180 minutes ( $A \cup C_{0-180 \mathrm{~min}}$ ), positive $A \cup C_{0-180 \mathrm{~min}}$, peak value, adjusted peak value, and peak time, were completed for glucose, insulin, and GLP-1. These calculations were performed according to a priori rules, described briefly here. AUC was calculated by the trapezoidal method for each variable. Positive $\mathrm{AUC}_{0-180 \text { min }}$ was also calculated using the trapezoidal method for only those values that were above the baseline (time 0 ) value for a given variable and any values that were below baseline were considered as zero. Peak value was the maximum value of all valid points over 0-180 minutes. Adjusted peak value was the peak value minus the value at $\mathrm{t}=0$. Peak time was the first time point during the $0-180$ minute interval at which the peak value was attained.

\section{Results \\ Subjects}

Thirty-seven subjects signed informed consent forms and were enrolled into the study. However, five were not included in the protocol evaluable analysis due to the following reasons: one subject had a missing value for primary variable, the same subject plus four others did not consume the experimental beverage/ meal within the allotted time and two of these voluntarily withdrew from the study. Demographic information and baseline characteristics of the 32 evaluable subjects are presented in Table 2.

\section{Plasma Blood Glucose}

There were no differences observed for baseline plasma glucose among the treatments $(137 \pm 5 \mathrm{mg} / \mathrm{dL}$ for OAT; $133 \pm 5 \mathrm{mg} / \mathrm{dL}$ for GTSN; $137 \pm 5 \mathrm{mg} / \mathrm{dL}$ for SBF). The adjusted plasma glucose values over the postprandial time-points 
Table 2: Demographics and baseline characteristics in evaluable subjects (mean \pm standard deviation; $\mathbf{n}=32$ )

\begin{tabular}{ll}
\hline Gender, $\mathbf{n}(\%)$ & \\
Male & $19(59.4)$ \\
Female & $13(40.6)$ \\
Age $(\mathrm{yrs})$ & $62.5 \pm 7.9$ \\
Height $(\mathrm{cm})$ & $170.6 \pm 11.9$ \\
Weight $(\mathrm{kg})$ & $83.51 \pm 14.54$ \\
BMI $\left(\mathrm{kg} / \mathrm{m}^{2}\right)$ & $28.5 \pm 2.8$ \\
Hemoglobin A1c $(\%)$ & $6.63 \pm 0.87$ \\
\hline
\end{tabular}

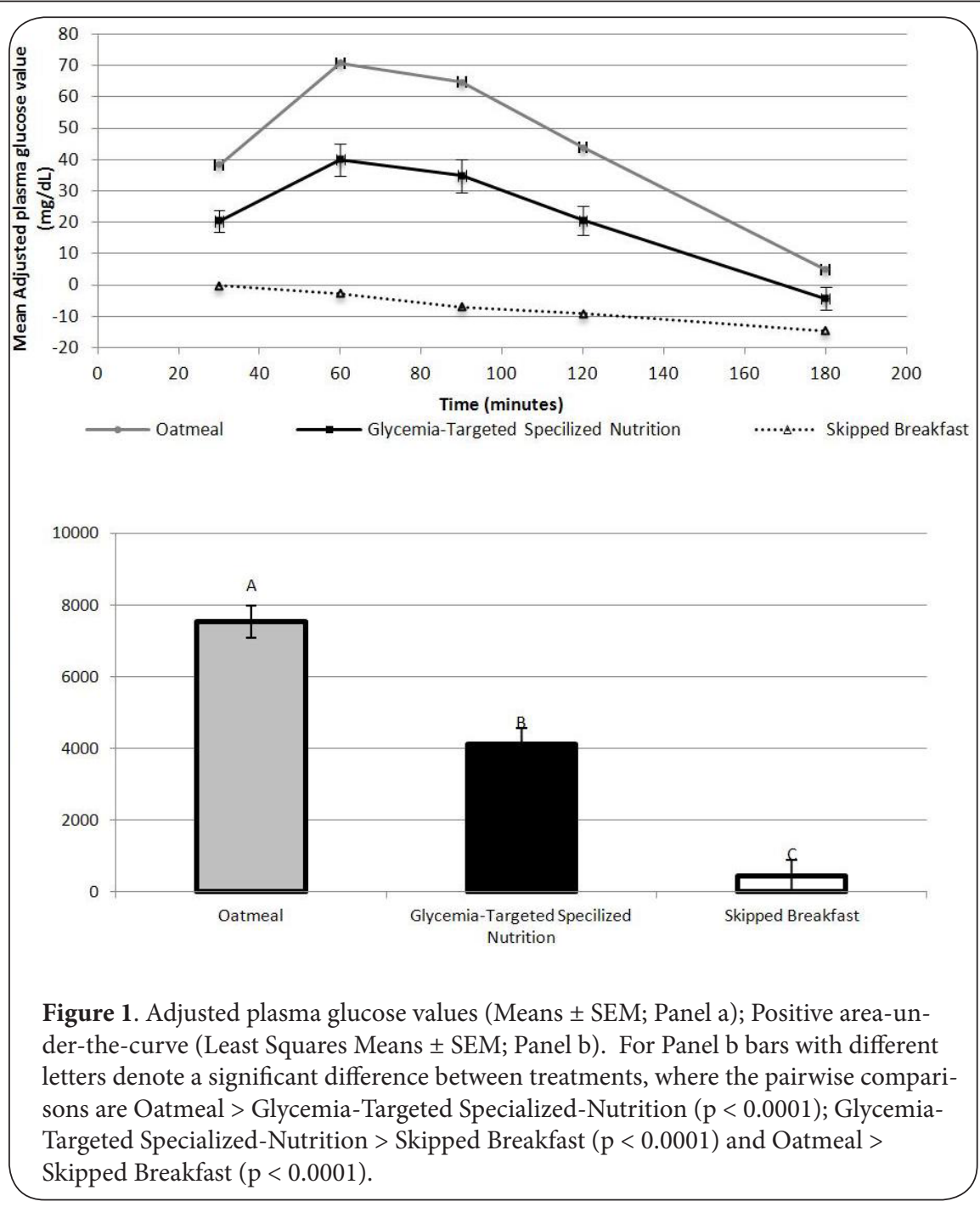

indicated a differential response among the three treatments, as can be seen by the separation of the median adjusted glucose response curves (Figure 1a). This visual difference was confirmed by assessing the glucose pAUCs for each treatment where GTSN elicited a 38\% (based on individual percent changes) lower pAUC than OAT (GTSN $4119 \pm 461$ $\left.(\mathrm{mg} / \mathrm{dL})^{*} \mathrm{~min}\right)$ compared to OAT $7531 \pm 461(\mathrm{mg} / \mathrm{dL})^{*} \mathrm{~min}$; repeated measures ANOVA; $p<0.0001$; Figure $1 \mathrm{~b}$ ). As expected the SBF treatment resulted in the smallest pAUC $\left(437 \pm 460(\mathrm{mg} / \mathrm{dL})^{*} \mathrm{~min}\right)$, due to the lack of caloric delivery. The peak plasma glucose (OAT $214 \pm 7 \mathrm{mg} / \mathrm{dL}$; GTSN $178 \pm$ $8 \mathrm{mg} / \mathrm{dL}$; SBF $142 \pm 7 \mathrm{mg} / \mathrm{dL} ; \mathrm{p}<0.0001$ for each pairwise comparison) and adjusted peak plasma glucose (OAT $76 \pm$ $4 \mathrm{mg} / \mathrm{dL}$; GTSN $46 \pm 4 \mathrm{mg} / \mathrm{dL} ; \mathrm{SBF} 5 \pm 4 \mathrm{mg} / \mathrm{dL} ; \mathrm{p}<0.0001$ for each pairwise comparison) response was found to be significantly different among all three treatments, with OAT eliciting the highest mean plasma glucose value. The mean peak plasma glucose response observed one hour after consumption of GTSN met the postprandial blood glucose of $<180 \mathrm{mg} / \mathrm{dL}$ per ADA recommendations [3]. This was not observed from the other caloric treatment, OAT.

\section{Serum Insulin}

The adjusted serum insulin curves showed similar postprandial insulin response for GTSN and OAT, while SBF was largely unaffected (Figure 2a). Statistically significant differences were observed such that GTSN resulted in a larger insulin pAUC compared to OAT treatment. Both the GTSN and OAT treatments resulted in high pAUC than SBF, as the non-caloric treatment did not elicit an insulinemic response (Figure $\mathbf{2 b}$ ). The peak and adjusted peak serum insulin responses from GTSN $(30 \pm 2$ and $22 \pm 2 \mu \mathrm{IU} / \mathrm{mL}$, respectively) were significantly higher than OAT $(25 \pm 2 \mu \mathrm{IU} /$ $\mathrm{mL} ; \mathrm{p}=0.0062$, and $18 \pm 2 \mu \mathrm{IU} / \mathrm{mL} ; \mathrm{p}=0.0162$, respectively). Consumption of both GTSN and OAT resulted in significantly higher peak and adjusted peak insulin levels compared to $\mathrm{SBF}(9 \pm 2 \mu \mathrm{lU} / \mathrm{mL}$ and $2 \pm 2 \mu \mathrm{lU} / \mathrm{mL}$, respectively; $\mathrm{p}<0.0001$ for both treatment group comparisons).

\section{Plasma GLP-1}

The median adjusted plasma GLP-1 curves over time revealed that GTSN elicited a stronger GLP-1 induction than OAT and SBF treatments (Figure 3a). This was corroborated by median 
a
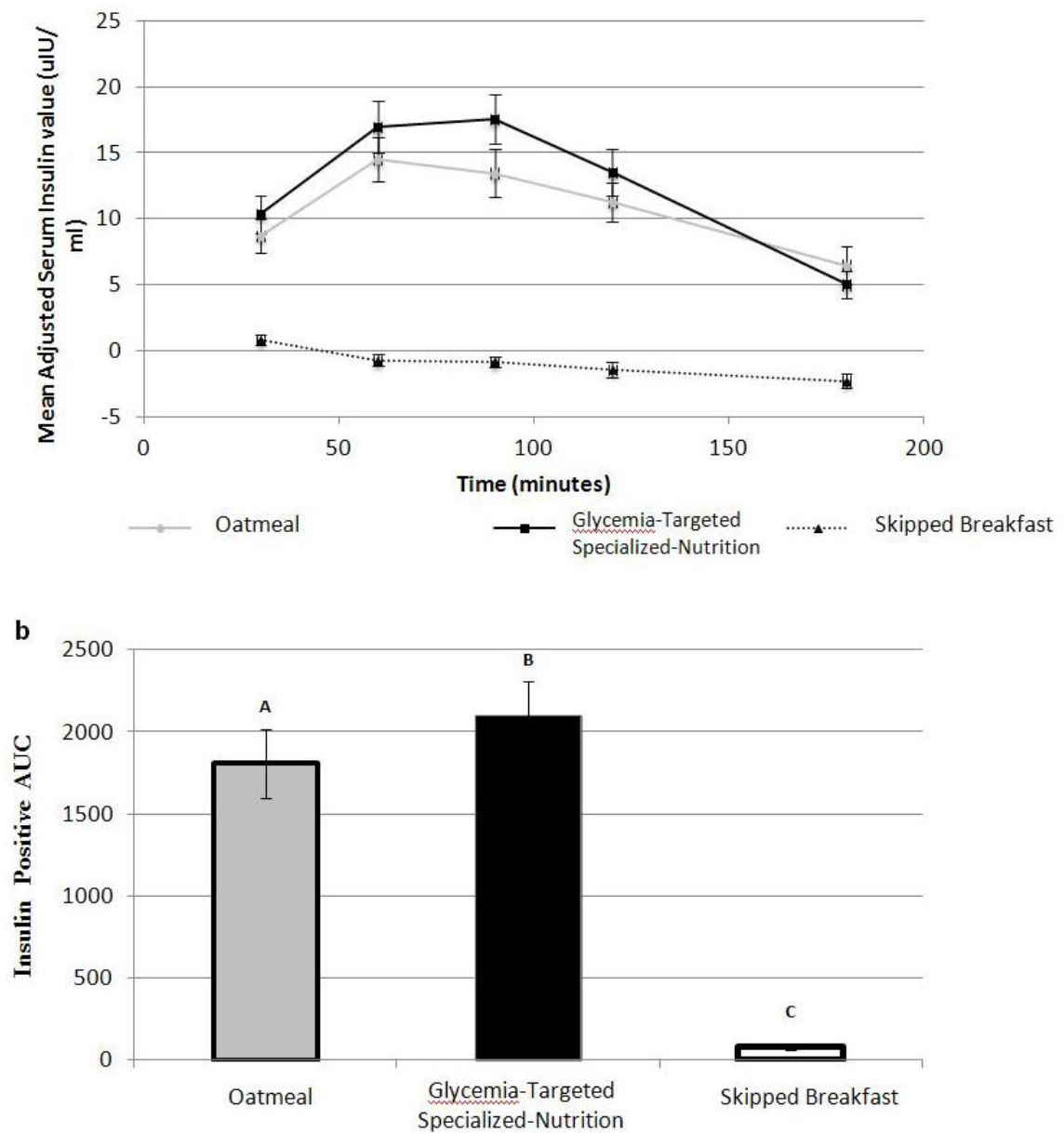

Figure 2. Adjusted serum insulin values (Means \pm SEM; Panel a); Positive area-under-thecurve (Least Squares Means \pm SEM; Panel b). For Panel b bars with different letters denote a significant difference between treatments, where the pairwise comparisons are Glycemia-Targeted Specialized-Nutrition $>$ Oatmeal $(\mathrm{p}=0.0162)$; Glycemia-Targeted Specialized-Nutrition and Oatmeal $>$ Skipped Breakfast $(\mathrm{p}<0.0001)$ and Oatmeal $>$ Skipped Breakfast $(\mathrm{p}<0.0001)$.

plasma GLP-1 pAUC, which was significantly increased after consumption of GTSN compared to OAT (Signed rank test; $\mathrm{p}<0.0001$; medians; GTSN 188 (pmol/L)*min compared to OAT 40 (pmol/L)*min) and GTSN compared to SBF (Signed rank test; $\mathrm{p}<0.0001 ; 188$ (pmol/L)*min compared to $1 \mathrm{pmol} /$ L)*min; Figure 3b). Median GLP-1 pAUC was elevated after consumption of GTSN by $280 \%$ (based on individual percent changes) compared to OAT and $995 \%$ (based on individual percent changes) compared to SBF. When comparing the median adjusted peak plasma GLP-1 responses among the breakfasts, GTSN (3.10 pmol/L) was associated with significantly higher response than OAT (0.80 pmol/L; $p=0.0004)$ and SBF (0.05 pmol/L; $p<0.0001)$. SBF elicited the lowest median adjusted peak plasma GLP-1 response, and was significantly lower than OAT $(p=0.0016)$.
Subjective Appetite Ratings and Energy Intake Subjective appetitive ratings were obtained and demonstrated that hunger, fullness, desire to eat and prospective consumption were all modulated by the caloric and non-caloric breakfasts. No significant differences in pAUC for hunger, fullness, desire to eat or prospective consumption were observed between the GTSN and OAT interventions. Hunger pAUC was significantly elevated after SBF (median; 1808) compared to both the OAT (109; $\mathrm{p}<0.0001)$ and GTSN (311; $\mathrm{p}=0.0081)$ interventions. Subjective fullness ratings pAUC were significantly lower from SBF (244) compared to OAT (3870; $p<0.0001)$ and GTSN (3016; $p<0.0001)$. In alignment with the appetitive pAUC responses for the caloric treatments, GTSN (1222 \pm 88 kcals) treatment resulted in no statistical difference in 


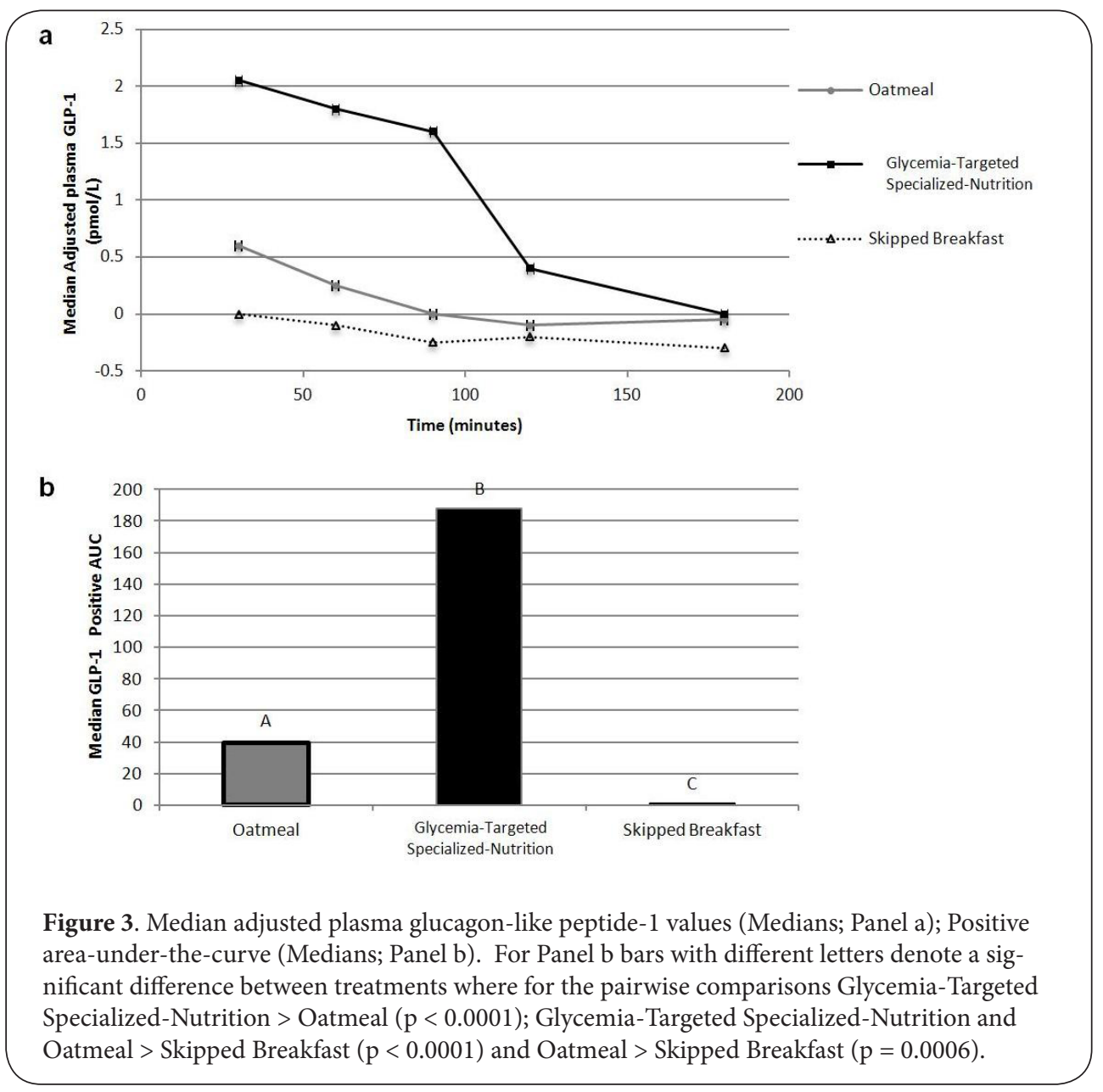

energy intake for the remainder of the study day compared to OAT ( $1171 \pm 88 \mathrm{kcals})$ or SBF (1177 $\pm 88 \mathrm{kcals})$. Paradoxically, despite the elevated hunger and depressed fullness observed after SBF, energy intake was not significantly increased.

\section{Discussion}

\section{Plasma Blood Glucose}

Glycemia-targeted specialized-nutrition has been demonstrated to provide metabolic benefits for people with diabetes as compared to standard nutritional formulas for glycemic control, GLP-1 response and weight loss [9,16$19,22]$. The current study is the first to indicate that GTSN formulas exert significantly lower postprandial glucose response as compared to a whole food breakfast (oatmeal) in people with T2DM. This finding emphasizes the impact of breakfast choice on postprandial glycemic excursions. The two caloric interventions in this study provided different amounts of total and available carbohydrate (available $\mathrm{CHO}=$ total $\mathrm{CHO}$ - fiber). GTSN supplied $29 \mathrm{~g}$ total $\mathrm{CHO}$ and $27 \mathrm{~g}$ available $\mathrm{CHO}$ whereas OAT provided $38 \mathrm{~g}$ total $\mathrm{CHO}$ and $32 \mathrm{~g}$ available $\mathrm{CHO}$. Providing lower total and available $\mathrm{CHO}$ contributes to the GTSN eliciting a lower glycemic response. Additionally, the GTSN consisted of a blend of slowly-digested, slowly-absorbed $\mathrm{CHO}$ sources which result in blunted glycemic response [22], while those carbohydrates in the OAT product are not specialized for this purpose.

Glycemic control can also be impacted by the mere act of consuming breakfast. In people with T2DM, post-breakfast hyperglycemia has been shown to occur more frequently than after other eating occasions, despite treatment with anti-hyperglycemic medicines/ insulin [23]. This observation may lead people with T2DM to skip breakfast in an attempt to control this phenomenon. In this study the absence of postprandial glycemic response observed when breakfast was skipped must be considered with caution. Studies clearly show that skipping breakfast exerts noted metabolic consequences such as a strong association with impaired fasting glucose [24] and lipids, a reduced postprandial insulin sensitivity in healthy obese women [25], and is the primary cause for hypoglycemia [26]. Further, breakfast skipping is positively associated with being overweight or obese from cross-sectional studies conducted in the US, Eastern 
Mediterranean, Taiwan and Asian/ Pacific regions [27-30]. Breakfast choices [26], as well as all food choices at all eating occasions that minimize postprandial hyperglycemia are important for reducing the risk of developing diabetes related micro- and macrovascular complications in individuals with type 2 diabetes [31,32]. To facilitate appropriate food choices that impart glycemic control and support weight management goals, medical nutritional therapy consisting of GTSN is often recommended and utilized in parallel with pharmacotherapy. However, diabetes dietary guidelines can be cumbersome. Due to their ease of use and previously discussed efficacy, meal or calorie replacements that are also glycemia-targeted have been incorporated as a recommended tool in several diabetesspecific nutritional plans $[33,34]$ and within the recently published Transcultural Diabetes-specific Nutritional Algorithms [4-6]. This study demonstrates that breakfast consumption in people with T2DM can be metabolically beneficial when appropriate glycemia-targeted breakfast choices are made and supports the use of GTSN at the breakfast eating occasion as recommended in the Transcultural Diabetes-specific Nutrition Algorithms [4-6].

\section{Plasma GLP-1 and Serum Insulin}

GLP-1 secretion by the L-cells of the intestinal lumen is stimulated by carbohydrate, protein and fat ingestion [35]. This hormone has a demonstrated role in inhibition of gastric acid secretion and gastric motility as well as enhancement of satiation [35]. The current research supports previous findings showing postprandial GLP-1 secretion in people with diabetes is elevated by the consumption of GTSN $[18,19,22]$. However, this study is the first to compare GLP-1 response after GTSN consumption compared to a whole food and breakfast skipping. The elevation in GLP-1 after eating is not unexpected, as it is known that GLP-1 secretion is directly related to macronutrient composition, specifically carbohydrate [36] and gastric distention (imparted by ingestion of a larger volume of food). However, the higher carbohydrate, larger volume treatment (OAT) neglected to elicit GLP-1 release equal to or greater than the lower carbohydrate, smaller volume GTSN. This differential response despite protein and energy matching with both carbohydrate content and volume favoring the OAT provision aligned with previous work indicating that the type of carbohydrate $[18,19,22]$ and monounsaturated fatty acids (MUFA) [37] are important for GLP-1 release in people with diabetes. Since the largest GLP-1 response was observed after the consumption of GTSN which had $9 \mathrm{~g}$ less total carbohydrate and $3.9 \mathrm{~g}$ more total fat (including MUFA) than OAT, is it suggestive that the slowly digesting, low glycemic carbohydrate blend and monounsaturated fat blend in GTSN plays an important role for GLP-1 response. This conclusion is supported by previous work that demonstrates slowly-digested carbohydrate and MUFA fat containing formulations of GTSN elicit a larger GLP-1 response compared to GTSN without slowly digesting carbohydrate [19] and a standard oral nutritional formulation [18,22].

Furthermore, despite GTSN eliciting similar postprandial serum insulin pAUC compared to OAT the incretin effect of GLP-1 appeared to be maintained. The peak and adjusted peak insulin levels reached after consumption of GTSN were higher than after OAT.

\section{Subjective Appetitive Response and Energy Intake} Physiologically, the consumption of breakfast has been associated with satiation and satiety [38], decreased body weight [39] and decreased risk for diabetes and CVD [40,41]. As expected, skipping breakfast resulted in the highest hunger and least fullness which were significantly different from the caloric treatments. However, the hunger and fullness observed from the skipped breakfast did not elicit acute changes in energy intake. This is likely due to the compulsory lunch meal consumed at the end of the meal tolerance test (which could not freely differ between treatments) thus leaving only the evening meals and snacks (if consumed) available for energy compensation. Subjective appetitive responses and total daily energy intake were similar after consumption of GTSN and OAT suggesting the similar impact on satiation and supporting the subsequent similarities in total energy intake.

\section{Study limitations}

The study limitations include the acute nature of the study treatments, thereby eliminating the extrapolation to more chronic and weight related outcomes. As such future work should characterize chronic outcomes and take into account the possibility of fatigue in regard to GTSN consumption by offering a variety of flavor options.

\section{Conclusion}

This research demonstrated that the utilization of GTSN improved glycemic control and elevated GLP-1 release compared to a healthful breakfast food (oatmeal) and breakfast skipping without negatively impacting appetitive response or energy intake. As this study was acute, it is recommended that future work assess similar outcomes over a prolonged ingestion period and potentially at different eating occasions. The current findings suggest that glycemia-targeted specialized nutrition containing slowly digested carbohydrates and MUFA provides unique metabolic benefits for people with T2DM when used as a meal replacement and are appropriate for incorporation into diabetes treatment algorithms.

\section{Competing interests}

$A A D, J S O, R A H$ and VAM are employees of Abbott Nutrition.

\section{Authors' contributions}

$A A D, R A H$ and VAM contributed to the study design. JSO completed all data analysis and all authors contributed to data 
interpretation. AAD prepared the manuscript and all authors contributing to its critical review and approval for publication.

\section{Funding disclosure}

The trials upon which this paper is based were funded by Abbott Nutrition, Columbus, $\mathrm{OH}$.

\section{Publication history}

Received: 28-Sep-2012 Revised: 01-Nov-2012

Accepted: 04-Dec-2012 Published: 13-Dec-2012

\section{References}

1. IDF Clinical Guidelines Task Force. Global guideline for Type 2 diabetes. Brussels: International Diabetes Federation, 2005. | Pdf

2. Nathan DM, Buse JB, Davidson MB, Ferrannini E, Holman RR, Sherwin $R$, Zinman $B$ : Medical management of hyperglycaemia in type 2 diabetes mellitus: a consensus algorithm for the initiation and adjustment of therapy: a consensus statement from the American Diabetes Association and the European Association for the Study of Diabetes. Diabetologia 2009, 52:17-30. | Article | PubMed

3. Standards of medical care in diabetes--2012. Diabetes Care 2012, 35 Suppl 1:S11-63. | Article | PubMed

4. Mechanick JI, Marchetti AE, Apovian C, Benchimol AK, Bisschop PH, Bolio-Galvis A, Hegazi RA, Jenkins D, Mendoza E, Sanz ML, Sheu WH, Tatti P, Tsang MW, Hamdy O: Diabetes-specific nutrition algorithm: a transcultural program to optimize diabetes and prediabetes care. Curr Diab Rep 2012, 12:180-194. | Article | PubMed Abstract | PubMed Full Text

5. Joshi SR, Mohan V, Joshi SS, Mechanick JI, Marchetti A: Transcultural diabetes nutrition therapy algorithm: the Asian Indian application. Curr Diab Rep 2012, 12:204-212. | Article | PubMed Abstract | PubMed Full Text

6. Su HY, Tsang MW, Huang SY, Mechanick JI, Sheu WH, Marchetti A: Transculturalization of a diabetes-specific nutrition algorithm: Asian application. Curr Diab Rep 2012, 12:213-219. | Article | PubMed Abstract | PubMed Full Text

7. Wadden TA, West DS, Neiberg RH, Wing RR, Ryan DH, Johnson KC, Foreyt JP, Hill JO, Trence DL, Vitolins MZ: One-year weight losses in the Look AHEAD study: factors associated with success. Obesity (Silver Spring) 2009, 17:713-722. | Article | PubMed Abstract | PubMed Full Text

8. Wadden TA, Neiberg RH, Wing RR, Clark JM, Delahanty LM, Hill JO, Krakoff J, Otto A, Ryan DH, Vitolins MZ: Four-year weight losses in the Look AHEAD study: factors associated with long-term success Obesity (Silver Spring) 2011, 19:1987-1998. | Article | PubMed Abstract | PubMed Full Text

9. Sun J, Wang $Y$, Chen $X$, Chen $Y$, Feng $Y$, Zhang $X$, Pan $Y$, Hu T, Xu J, Du L, Zhou W, Zhao H, Riley RE, Mustad VA: An integrated intervention program to control diabetes in overweight Chinese women and men with type 2 diabetes. Asia Pac J Clin Nutr 2008, 17:514-524. | Pdf | PubMed

10. Wyatt HR, Grunwald GK, Mosca CL, Klem ML, Wing RR, Hill JO: Longterm weight loss and breakfast in subjects in the National Weight Control Registry. Obes Res 2002, 10:78-82. | Article | PubMed

11. Heymsfield SB, van Mierlo CA, van der Knaap HC, Heo M, Frier HI: Weight management using a meal replacement strategy: meta and pooling analysis from six studies. Int J Obes Relat Metab Disord 2003, 27:537-549. | Article | PubMed

12. Ditschuneit HH, Flechtner-Mors M, Johnson TD, Adler G: Metabolic and weight-loss effects of a long-term dietary intervention in obese patients. Am J Clin Nutr 1999, 69:198-204. | Article | PubMed

13. Li Z, Hong K, Saltsman P, DeShields S, Bellman M, Thames G, Liu Y, Wang HJ, Elashoff R, Heber D: Long-term efficacy of soy-based meal replacements vs an individualized diet plan in obese type II DM patients: relative effects on weight loss, metabolic parameters, and C-reactive protein. Eur J Clin Nutr 2005, 59:411-418. | Article | PubMed

14. Jenkins DJ, Taylor RH, Wolever TM: The diabetic diet, dietary carbohydrate and differences in digestibility. Diabetologia 1982,
23:477-484. | Article | PubMed

15. Fix BM, Lowe W, Cockram D, Craig L: Effect of a liquid nutritional supplement containing a novel carbohydrate system on glucose tolerance in subjects with type 2 diabetes. Ann Nutr Meta 2001, 45:227.

16. Elia M, Ceriello A, Laube H, Sinclair AJ, Engfer M, Stratton RJ: Enteral nutritional support and use of diabetes-specific formulas for patients with diabetes: a systematic review and meta-analysis. Diabetes Care 2005, 28:2267-2279. | Article | PubMed

17. Tatti P, Mauro P, Neri M, Pipicelli G, Mussad V: Effect of a low-calorie high nutritional value formula on weight loss in type 2 diabetes mellitus. Mediterr J Nutr Metab 2010, 3:65-69. | Article

18. Alish CJ, Garvey WT, Maki KC, Sacks GS, Hustead DS, Hegazi RA, Mustad VA: A diabetes-specific enteral formula improves glycemic variability in patients with type 2 diabetes. Diabetes Technol Ther 2010, 12:419-425. | Article | PubMed

19. Voss AC, Maki KC, Garvey WT, Hustead DS, Alish C, Fix B, Mustad VA: Effect of two carbohydrate-modified tube-feeding formulas on metabolic responses in patients with type 2 diabetes. Nutrition 2008, 24:990-997. | Article | PubMed

20. Standardization of the oral glucose tolerance test. Report of the Committee on Statistics of the American Diabetes Association June 14, 1968. Diabetes 1969, 18:299-307. | PubMed

21. Wolever TM, Jenkins DJ, Jenkins AL, Josse RG: The glycemic index: methodology and clinical implications. Am J Clin Nutr 1991, 54:846854. | Article | PubMed

22. Williams JA, Almeida JG., Matia MM, Sanz-Paris A, Noss MJ, et. al: Amount and type of carbohydrate in diabetes-specific nutritional formulas affects glycemic response in patients with type 2 diabetes. Clinical Nutrition Supplements 2009,4(S2):168-168. | Article

23. Carroll MF, Gutierrez A, Castro M, Tsewang D, Schade DS: Targeting postprandial hyperglycemia: a comparative study of insulinotropic agents in type 2 diabetes. J Clin Endocrinol Metab 2003, 88:52485254. | Article | PubMed

24. Li Y, Nemoto T, Tobimatsu S, Saito M, Ebata M, et al: Relationship between skipping breakfast and impaired fasting glucose along with cardiovascular and pre-diabetes condition risk factors in apparently healthy subjects. Endocrinology Studies 2011, 1:76-80. | Pdf

25. Farshchi HR, Taylor MA, Macdonald IA: Beneficial metabolic effects of regular meal frequency on dietary thermogenesis, insulin sensitivity, and fasting lipid profiles in healthy obese women. Am J Clin Nutr 2005, 81:16-24 . | Article | PubMed

26. Morris SF and Wylie-Rosett J: Medical nutrition therapy: a key to diabetes management and prevention. Clinical Diabetes 2010, 1:1218. | Article

27. Horikawa C, Kodama S, Yachi Y, Heianza Y, Hirasawa R, Ibe Y, Saito K, Shimano H, Yamada N, Sone H: Skipping breakfast and prevalence of overweight and obesity in Asian and Pacific regions: a meta-analysis Prev Med 2011, 53:260-267. | Article | PubMed

28. Musaiger AO: Overweight and obesity in eastern mediterranean region: prevalence and possible causes. J Obes 2011, 2011:407237. Article | PubMed Abstract | PubMed Full Text

29. Huang CJ, Hu HT, Fan YC, Liao YM, Tsai PS: Associations of breakfast skipping with obesity and health-related quality of life: evidence from a national survey in Taiwan. Int J Obes (Lond) 2010, 34:720-725. | Article | PubMed

30. Song WO, Chun OK, Obayashi S, Cho S, Chung CE: Is consumption of breakfast associated with body mass index in US adults? J Am Diet Assoc 2005, 105:1373-1382. | Article | PubMed

31. Heine RJ, Dekker JM: Beyond postprandial hyperglycaemia: metabolic factors associated with cardiovascular disease. Diabetologia 2002, 45:461-475. | Article | PubMed

32. Nalysnyk L, Hernandez-Medina M, Krishnarajah G: Glycaemic variability and complications in patients with diabetes mellitus: evidence from a systematic review of the literature. Diabetes Obes Metab 2010, 12:288-298. | Article | PubMed

33. Hamdy O, Zwiefelhofer D: Weight management using a meal replacement strategy in type 2 diabetes. Curr Diab Rep 2010, 10:159164. | Article | PubMed 
Devitt et al. Journal of Diabetes Research \& Clinical Metabolism 2012,

http://www.hoajonline.com/journals/pdf/2050-0866-1-20.pdf

34. Seagle HM, Strain GW, Makris A, Reeves RS: Position of the American Dietetic Association: weight management. J Am Diet Assoc 2009, 109:330-346. | Article | PubMed

35. Naslund E, Barkeling B, King N, Gutniak M, Blundell JE, Holst JJ, Rossner S, Hellstrom PM: Energy intake and appetite are suppressed by glucagon-like peptide-1 (GLP-1) in obese men. Int J Obes Relat Metab Disord 1999, 23:304-311. | Article | PubMed

36. Cummings $D E$, Overduin J: Gastrointestinal regulation of food intake. J Clin Invest 2007, 117:13-23. | Article | PubMed Abstract | PubMed Full Text

37. Paniagua JA, de la Sacristana AG, Sanchez E, Romero I, Vidal-Puig A, Berral FJ, Escribano A, Moyano MJ, Perez-Martinez P, Lopez-Miranda J, Perez-Jimenez F: A MUFA-rich diet improves posprandial glucose, lipid and GLP-1 responses in insulin-resistant subjects. J Am Coll Nutr 2007, 26:434-444. | Article | PubMed

38. de Castro JM: The time of day of food intake influences overall intake in humans. J Nutr 2004, 134:104-111. | Article | PubMed

39. Bazzano LA, Song Y, Bubes V, Good CK, Manson JE, Liu S: Dietary intake of whole and refined grain breakfast cereals and weight gain in men. Obes Res 2005, 13:1952-1960. | Article | PubMed

40. Albertson AM, Thompson D, Franko DL, Kleinman RE, Barton BA, Crockett $\mathrm{SJ}$ : Consumption of breakfast cereal is associated with positive health outcomes: evidence from the National Heart, Lung, and Blood Institute Growth and Health Study. Nutr Res 2008, 28:744-752. | Article | PubMed

41. Albertson AM, Affenito SG, Bauserman R, Holschuh NM, Eldridge AL, Barton BA: The relationship of ready-to-eat cereal consumption to nutrient intake, blood lipids, and body mass index of children as they age through adolescence. J Am Diet Assoc 2009, 109:1557-1565. | Article | PubMed 